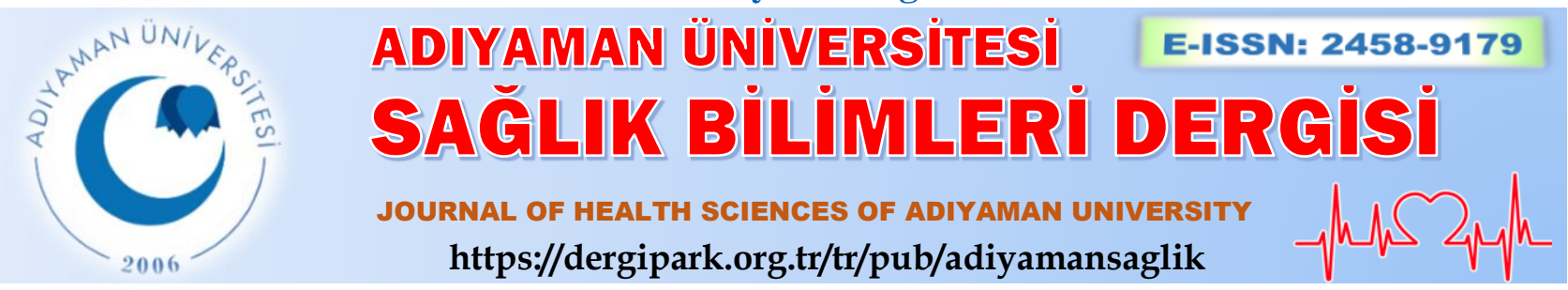

Özgün Araştırma/Research Article

\title{
Fazla kilolu ve obez kadınlarda 30 dakika egzersiz kilo kaybı üzerine etkili midir?
}

\section{Is 30 minutes of exercise effective on weight loss in overweight and obese women?}

\author{
Emre BASKAN ${ }^{1 @(D)}$ Özden BASKAN ${ }^{2}$ (D) Orçin Telli ATALAY ${ }^{1}$ (D) Nesrin YAĞCI ${ }^{1}$ \\ ${ }^{1}$ Pamukkale Üniversitesi, Fizik Tedavi ve Rehabilitasyon Yüksekokulu, 20160, Denizli-Türkiye \\ ${ }^{2}$ Sinerji Sağlıklı Yaşam Merkezi, 20160, Denizli-Türkiye
}

Atıf gösterme/Cite this article as: Baskan E, Baskan Ö, Atalay OT, Yağcı N. Fazla kilolu ve obez kadınlarda 30 dakika egzersiz kilo kaybı üzerine etkili midir? ADYÜ Sağllk Bilimleri Derg. 2020;6(3):288-294. doi:10.30569.adiyamansaglik. 739063

$\ddot{O} \mathbf{z}$

Amaç: Çalışmamızın amacı fazla kilolu ve obez kadın katılımcılarda, 30 dakika süren aerobik egzersizle kombine edilmiş döngüsel direnç egzersizlerinin, vücut kompozisyonu üzerindeki etkilerini belirlemektir.

Gereç ve Yöntem: $\mathrm{Bu}$ çalışma yaşları 20-54 yıl arasında $(30,14 \pm 10,62$ yıl) 50 sağlıklı kadın ile gerçekleştirilmiştir. Katılımcılar beden kitle indeksine göre fazla kilolu ve obez olmak üzere iki gruba ayrıldı. Katılımcıların demografik verileri ile vücut kompozisyon değerleri egzersiz öncesinde ve sonrasında kaydedildi. Katılımcılar, haftada 3 gün, 12 hafta egzersiz programına alındı.

Bulgular: Katılımcılarda kilo verme ve vücut kompozisyon değerlerindeki gelişmeler açısından bu tip egzersizlerin etkili olduğu görülmüştür $(p=0,001)$. Gruplar karşılaştırıldığında obez grupta kilo $(p=0,002)$ ve iç yağ oranı $(p=0,005)$ kaybının daha fazla olduğu bulunmuştur.

Sonuç: Otuz dakika süren aerobik egzersizle kombine döngüsel direnç egzersizler kilo verme amaçlı kullanılabilecek kısa süreli, etkili bir alternatiftir.

Anahtar Kelimeler: Döngüsel Dirençli Egzersiz; Vücut Kompozisyonu; Obezite.

\begin{abstract}
Aim: The aim was to determine the effects of cyclic resistance exercises combined with aerobic exercise on body composition in overweight and obese women.

Materials and Methods: This study was performed with 50 healthy women aged between 20-54 years (30.14 \pm 10.62 years). Participants were divided two groups as overweight and obese. Demographical and body composition values were recorded before and after the exercise. Participants performed 12-week exercise program.

Results: This type of exercise has been shown to be effective in terms of improvements in weight loss and body composition values $(p=0.001)$. It was found that weight $(p=0.002)$ and internal fat ratio $(p=0.005)$ loss was higher in the obese group.

Conclusion: Cyclic resistance exercises combined with thirty minutes of aerobic exercise is a short-term, effective alternative that can be used for weight loss.

Keywords: Cyclic Resistance Exercise; Body Composition; Obesity.
\end{abstract}

Yazışma Adresi/Address for Correspondence: Emre BASKAN, Pamukkale Üniversitesi, Fizik Tedavi ve Rehabilitasyon Yüksekokulu, 20160, Denizli-Türkiye, E-mail: ebaskan@pau.edu.tr

Geliş Tarihi/Received:19.05.2020 Kabul Tarihi/Accepted:08.09.2020

Yayım Tarihi/Published online:03.12.2020

Bu eser, Creative Commons Atıf-GayriTicari 4.0 Uluslararası Lisansı ile lisanslanmıştır. Telif Hakk1 @ 2020 Adıyaman Üniversitesi Rektörlüğü 


\section{Giriş}

Düzenli olarak yapılan ve kişiye özel olarak hazırlanan egzersiz eğitiminin bireylerin beden kitle indeksi (BKİ), kilo, vücut kompozisyonu gibi parametrelerinde iyileşmeyi sağladığı ya da var olan uygun düzeyleri koruduğu bilinmektedir. ${ }^{1}$ Egzersiz yapmayan bireylerin koroner kalp hastalıkları, yüksek tansiyon, yüksek kolesterol, kanser, obezite ve kas iskelet rahatsılıkları gibi hipokinetik hastalıklara yakalanma riski oldukça yüksektir. ${ }^{2}$ Düzenli fiziksel aktivite erken ölümleri önlemekte, yaşamın kaliteli olarak sürdürülmesine destek olmaktadır. ${ }^{3}$

Vücut kompozisyonunun iyileştirilmesi gibi amaçlarla farklı tiplerde egzersizler yapılsa da literatürde en sı aerobik egzersizlerin kullanıldığı ve etkilerinin araştırıldığı görülmektedir. Aerobik egzersizlerin genel sağlık durumu, fiziksel aktivite, vücut kompozisyonu, vücut yağ oranı, kuvvet, esneklik, dayanıkl1lık ve kendine güven üzerinde olumlu etkisinin olduğu bilinmektedir. ${ }^{4}$ Buna ek olarak düzenli aerobik egzersizlerin yapılmasının yağ kütlesi ve kiloda azalmayı, HDL kolesterol ve insülin miktarında artışı sağladığı yapılan çalışmalarda görülmüştür. ${ }^{4,5}$

Sağlığı ve yaşam kalitesini üst düzeyde devam ettirmede aerobik egzersizlerin yanı sıra direnç egzersizleri de sıklıkla kullanılan egzersizler arasında bulunmaktadır. ${ }^{6}$ Postür ve ekstremite kaslarına yönelik yapılan direnç egzersizleri kas kuvvetinde artış, postür problemlerinde azalma ve aerobik egzersizler gibi vücutta fizyolojik olarak da iyileşme sağlamaktadır. ${ }^{6}$

Direnç egzersizlerinin bir alt türü olan döngüsel direnç egzersizleri ise, literatürde aerobik veya direnç egzersizleri kadar üzerinde çalışılmamış olmakla birlikte, pratikte özellikle spor merkezlerinde oldukça rağbet gören bir egzersiz türüdür. Kasa verilecek direnç, farklı bölge kaslarına yönelik dizayn edilen direnci ayarlanabilen hidrolik egzersiz cihazları ile sağlanır. Döngüsel direnç egzersizleri hareketliliği, kuvveti ve dayanıklılığı eş zamanlı olarak geliştirmek için kullanılan bir yöntemdir. Literatürde kas kuvveti ve kardiyovasküler dayanıklılı̆̆ arttırırken, vücut yağ oranını ve kiloyu azaltarak vücut kompozisyonunda iyileşme sağladığı bildirilmiştir. ${ }^{6}$ Döngüsel direnç egzersizlerinin fiziksel uygunluğun her yönüne hitap etmesi, değişik egzersizler ile ilgi çekici olması, egzersizi monotonluktan kurtararak motive etmesi ve sürekli canlı tutması, bu egzersiz tipini tercih eden kişi sayısını arttırmaktadır. ${ }^{7}$ Ayrıca bu yöntemde yorgunluk daha iyi kontrol edildiğinden, aynı zaman periyodunda daha fazla çalışma yapılabilmesine de izin vermektedir. Aerobik destekli döngüsel direnç egzersizleri vücudun, farklı kas gruplarını içeren alternatif sürelere uyum sağlaması açısından tercih edilebilir bir yöntem olabilir. $6,7,8$ Konvansiyonel egzersizlerin uzamasından kaynaklanan kardiyovasküler tehlikeleri en aza indirgeyecek program yapısına sahiptir. ${ }^{8}$ Döngüsel direnç egzersiz program1, yetişkinler ve yaşlılar için güvenlidir, çünkü eğitim sırasında yaralanma riski çok azdır. Ayrıca egzersize bir grup olarak katılmak, programlara katılımı devam ettirme isteğini arttırarak kişilerde psikolojik ve sosyal faydalara sebep olabilir. ${ }^{8,9,10}$ Amerikan Spor Hekimliği Birliği, kilo vermek için haftada 150 ila 250 dakika egzersiz yapılmasını önermekle birlikte alternatif olarak haftada 3 gün 20-60 dakika şiddetli egzersiz programlarının da uygun olabileceğini belirtmektedir. ${ }^{11}$ Zamanın önem kazandığ günümüzde sağllklı kalmak ve kilo vermek için az zaman harcayarak en etkili yöntemi seçmek önem arz etmektedir.

$\mathrm{Bu}$ çalışma fazla kilolu ve obez kadın katılımcılarda, 30 dakika süren aerobik egzersizle döngüsel dirençli egzersiz kombinasyonunun etkilerini belirlemek ve döngüsel direnç egzersizlerinin vücut kompozisyonu üzerine etkileri ile ilgili literatüre katkıda bulunmak amaciyla planlanmıştır.

\section{Gereç ve Yöntem}

Çalışmamız Denizli ilinde egzersiz yapmak ve kilo vermek amacıyla, sağlıklı yaşam merkezi ve ilgili üniversitenin Fizik Tedavi ve Rehabilitasyon birimine başvuran ve dâhil etme kriterlerine uyan 50 gönüllü kadın katılımcıdan oluşmuştur. Çalışmaya yaş aralığı 20-54 yıl yaş ortalaması $30,14 \pm 10,62$ 
y1l olan, sedanter, mevcut bir egzersiz programına dahil olmayan, BKI $25 \mathrm{~kg} / \mathrm{m}^{2}$ üzerinde olan kadın katılımcılar dahil edilmiştir. Yapılan güç analizi sonucunda çalışmaya en az 50 kişi alındığında \%95 güven düzeyinde $\% 80$ güç elde edilebileceği hesaplanmıştır. Katılımcılardan egzersiz yapmalarında herhangi bir sakınca olmadığına dair sağlık raporu istenmiştir. Egzersiz yapmayı engelleyecek belirlenmiş bir sağlık problemi olan, herhangi bir egzersiz veya diyet programına devam eden kadınlar çalışmamıza dâhil edilmemiştir. Fazla kilo dışında ek bir sağlık problemi olmayan, sedanter ve gönüllü 50 kadın katılımcı, BKI'lerine göre fazla kilolu $(n=25$, BKİ:25$\left.29,99 \mathrm{~kg} / \mathrm{m}^{2}\right)$ ve obez $(\mathrm{n}=25$, BKİ:30-34,99 $\mathrm{kg} / \mathrm{m}^{2}$ ) olmak üzere 2 gruba ayrılarak 12 haftalık aerobik egzersizle kombine döngüsel dirençli egzersiz eğitim programına alınmıştır.

\section{Değerlendirme}

Katılımcıların cinsiyet, yaş, meslek gibi bilgileri ile bel-kalça çevresi, bel-kalça oranı gibi bilgiler egzersiz programı öncesinde ve sonrasinda hazırlanan veri formuna kaydedilmiştir. Vücut kompozisyonu ile ilgili yağ oranı, su oranı, kas oranı, iç yağ oranı ve kilo yüzdesi değerlendirmeleri biyoelektrik empedans analizörü (Tanita BC 601 Innerscan Vücut Analiz Cihazı) ile yapılmıştır.

Çalışmamızda kadın katılımcıların vücut kompozisyonları biyoelektrik empedans analizi ile değerlendirilmiştir. Biyoelektrik empedans analizi vücuttan geçirilen elektrik akımına yağ dokusunun verdiği direncin diğer dokulara göre farklı olması prensibine dayanan; vücut yağ kütlesinin objektif şekilde hesaplanması için kullanılan, geçerliği ve güvenirliği yüksek bir ölçüm metodudur. ${ }^{12} \mathrm{Bu}$ çalışmada biyoelektrik empedans analizi için Tanita BC 601 Innerscan Vücut Analizi Cihazı kullanılmıştır. Katılımcı, analizatöre çıplak ayak ile basacak şekilde, üzerindeki takıları çıkararak cihazın üzerindeki uygun yerlere basacak şekilde pozisyonlanmış ve vücut ağırlığ ile yağ kütlesi ölçülmüştür. Kıyafet ağırlığı dara olarak düşülmüştür. Bel çevresi ayakta duruş pozisyonunda umblikus hizasından, yanlarda subkostal bölgeden, kollar yana açıkken ölçülmüştür. Kalça çevresi önde simfizis pubis, arkada gluteal bölgenin en çıkıntılı kısmından ayakta ölçülmüştür. Ölçümler, esnek olmayan mezura ile iki tekrarlı yapılmıştır. ${ }^{13}$ Vücut kompozisyonu ile ilgili bel/kalça oranı, yă oranı, su oranı, kas oranı, iç yağ oranı ve kilo yüzdesi değerlendirmeleri egzersiz programı öncesinde ve sonrasında kaydedilmiştir.

Egzersiz programı: Katılımcilar, her seansta farklı bölge kaslarına 30 sn hidrolik izokinetik cihaz üzerinde direnç egzersizleri (hidrolik izokinetik cihazlar; torso twist, biceps-triceps, butterfly, leg curl, gluteahamstring, inner-outer uyluk, abdominal, shoulder press, leg press), $30 \mathrm{sn} 60 \times 60 \mathrm{~cm}$ boyutlarında $5 \mathrm{~cm}$ yüksekliğinde egzersiz platformları eşliğinde aerobik egzersiz olmak üzere 3 set, toplam $30 \mathrm{dk}$. olacak şekilde haftada 3 gün ve toplam 12 hafta egzersiz programlarına dâhil edilmişlerdir. Aerobik egzersizler üst, alt aktremiteler ve gövde kaslarını çalıştıracak şekilde hedef kalp atım sayılarının \%50-60 şiddetinde planlanmıştır. Hidrolik izokinetik cihazlar üst, alt ekstremiteleri dirençli çalıştıracak şekilde 9 ayrı cihazdır. Direnç, kişinin uyguladığ 1 kuvvete karşılık oluşur ve ayarlanabilir niteliktedir. Egzersizler durmaksızın 30 dakika boyunca 30 sn direnç 30 sn aerobik egzersizler olarak döngü halindedir. Egzersizler fizyoterapist ve deneyimli 2. kademe fitness antrenörü tarafından takip edilmiştir. Çalışma öncesi egzersiz etkisini daha açı gözlemlemek amacıyla katılımcılara özel bir diyet programı verilmemiştir.

\section{Verilerin analizi}

Çalışma sonucunda elde edilen veriler SPSS 22.0 paket programiyla analiz edilmiştir. Tanımlayıcı bilgilerin ortalama, frekans dağılımları, minimum-maksimum, standart sapma, yüzde değerleri hesaplanmıştır. Verilerin normal dağılıma uygunluğuna One-Sample Shapiro Wilk Testi ile karar verilmiştir. Aerobik egzersizle kombine döngüsel dirençli egzersiz eğitim programı öncesi ve sonrasında etkinliğinin değerlendirilmesi için bağımlı örneklem $t$ testi, grupların tedavi sonrası fark değerlerinin karşılaştırılmasında bağımsız grup $\mathrm{t}$ testi kullanılmıştır. Anlamlılık değerinin 0,05 'inaltında olduğu durumlar istatistiksel 
olarak anlamlı sonuçlar şeklinde değerlendirilmiştir.

\section{Bulgular}

Çalışmaya fazla kilolu ( $\mathrm{n}=25)$ (BMI $>25$ $29,99)$ ve obez $(n=25)(B M I>30-34,99)$ yaş ortalamaları $30,14 \pm 10,62$ y1l olan toplam 50 gönüllü kadın katılımcı dâhil edilmiştir. Grupların yaş dağılımları homojendi. Yaş ortalamas1 28,56 $\pm 9,89$ y1l olan fazla kilolu katılımcıların egzersiz programı öncesi ve sonrası vücut kompozisyon değerleri Tablo 1' de gösterilmektedir. Egzersiz programı sonrası fazla kilolu katılımcilarda kas ve vücut su oranı değerlerinde artış, kilo, BMI, kas oran1, iç yağ oranı, yağ oranı yüzdesi ve bel-kalça oranında istatistiksel olarak anlamlı düzeyde azalma gözlendi $(p<0,05)$.

Tablo 1. Fazla kilolu katılımcılarda egzersiz öncesi ve sonrası vücut kompozisyon değerleri

\begin{tabular}{lccc}
\hline $\begin{array}{l}\text { Vücut Kompozisyon } \\
\text { Değerleri }\end{array}$ & $\begin{array}{c}\text { Egzersiz Öncesi } \\
\text { Ortalama }\end{array}$ & $\begin{array}{c}\text { Egzersiz Sonrası } \\
\text { Ortalama }\end{array}$ & $\boldsymbol{p}^{*}$ \\
\hline Vücut ağırlı̆̆1 (kg) & $74,07 \pm 7,04$ & $69,26 \pm 7,05$ & 0,001 \\
BKİ (kg/m2) & $28,16 \pm 1,33$ & $26,21 \pm 1,57$ & 0,001 \\
Su Oranı (\%) & $46,70 \pm 3,01$ & $48,61 \pm 2,24$ & 0,001 \\
Kas Oranı (kg) & $45,57 \pm 3,12$ & $47,12 \pm 3,39$ & 0,043 \\
İç Yağ Oranı (\%) & $04,40 \pm 1,44$ & $03,64 \pm 1,52$ & 0,001 \\
Yağ Oranı (\%) & $35,14 \pm 4,13$ & $31,37 \pm 3,45$ & 0,001 \\
Bel-Kalça Oranı (cm) & $0,80 \pm 0,55$ & $0,78 \pm 0,06$ & 0,001 \\
\hline
\end{tabular}

kg: Kilogram; BKİ: Beden Kitle İndeksi; m:metre; \%:Yüzde * Paired Samples T

Yaş ortalaması $31,72 \pm 11,27$ yıl olan obez katılımcıların egzersiz programı öncesi ve sonrası vücut kompozisyon değerleri Tablo 2'de gösterilmektedir. Egzersiz programı sonras1 obez katılımcilarda vücut su oranı değerlerinde artış, kilo, BMI, kas oranı, iç yăg oranı, yağ oranı yüzdesi ve bel-kalça oranında anlamlı düzeyde azalma gözlendi $(p<0,05)$.

Tablo 2. Obez katılımcılarda egzersiz öncesi ve sonrası vücut kompozisyon değerleri

\begin{tabular}{lccc}
\hline $\begin{array}{l}\text { Vücut Kompozisyon } \\
\text { Değerleri }\end{array}$ & $\begin{array}{c}\text { Egzersiz Öncesi } \\
\text { Ortalama }\end{array}$ & $\begin{array}{c}\text { Egzersiz Sonrası } \\
\text { Ortalama }\end{array}$ & $\boldsymbol{p}^{*}$ \\
\hline Vücut ağırlığı (kg) & $93,36 \pm 9,03$ & $85,82 \pm 9,34$ & 0,001 \\
BKİ (kg/m2) & $34,96 \pm 3,37$ & $32,04 \pm 3,43$ & 0,001 \\
Su Oranı (\%) & $41,84 \pm 2,46$ & $43,46 \pm 2,79$ & 0,001 \\
Kas Oranı (kg) & $50,95 \pm 3,53$ & $50,02 \pm 3,53$ & 0,036 \\
İ̧ Yağ Oranı (\%) & $8,72 \pm 2,50$ & $7,12 \pm 2,27$ & 0,001 \\
Yağ Oranı (\%) & $42,28 \pm 3,52$ & $39,53 \pm 4,14$ & 0,001 \\
Bel-Kalça Oranı $(\mathrm{cm})$ & $0,80 \pm 0,05$ & $0,78 \pm 0,06$ & 0,001 \\
\hline
\end{tabular}

kg: Kilogram; BKİ: Beden Kitle İndeksi; m:metre; \%Yüzde * Paired Samples T Testi

Her iki grubun da kilo kaybı, vücut kompozisyon parametrelerinin delta değerleri, egzersiz programı öncesindeki verilerden, egzersiz programı sonrasındaki verilerin fark1 alınarak hesaplanmıştır. Fazla kilolu ve obez katılımciların egzersiz programı sonrasındaki delta değerleri karşılaştırıldığında kilo kaybı $(p=0,002)$, BKİ $(p=0,007)$, kas oranındaki artış $(p=0,004)$ ve iç yağ oranındaki azalma $(p=0,005)$ obez katılimcilar lehine anlamlı olarak bulunmuştur (Tablo 3). Obez katılımcılarda egzersizin kilo verme ve vücut kompozisyon değerlerinde daha etkili sonuçlar elde edilmiştir.

Tablo 3. Grupların kilo kaybı ve vücut kompozisyon değerlerinin egzersiz programı sonrasındaki fark değerlerinin karşılaştırılması

\begin{tabular}{lccc}
\hline $\begin{array}{l}\text { Vücut Kompozisyon } \\
\text { Değerleri }\end{array}$ & Fazla Kilolu Delta $(\boldsymbol{\Delta})$ & Obez Delta $(\Delta)$ & $\boldsymbol{p}^{*}$ \\
\hline Vücut ağırlığı $(\mathrm{kg})$ & $-4,81 \pm 0,01$ & $-7,54 \pm 0,31$ & 0,002 \\
BKİ (kg/m2) & $-1,95 \pm 0,24$ & $-2,92 \pm 0,06$ & 0,007 \\
Su Oranı (\%) & $2,41 \pm-0,77$ & $1,62 \pm 0,33$ & 0,567 \\
Kas Oranı (kg) & $1,55 \pm 0,27$ & $-1,93 \pm 0,00$ & 0,004 \\
İç Yağ Oranı (\%) & $-0,76 \pm 0,08$ & $-1,60 \pm-0,23$ & 0,005 \\
Yağ Oranı (\%) & $-3,77 \pm-0,68$ & $-2,75 \pm 0,62$ & 0,267 \\
Bel-Kalça Oranı (cm) & $-0,02 \pm-0,05$ & $0,02 \pm 0,00$ & 0,001 \\
\hline
\end{tabular}




\section{Tartışma}

Çalışmamızda kadınlarda 30 dakika süren aerobik egzersizle kombine döngüsel dirençli egzersizlerin, kilo verme ve diğer vücut parametreleri üzerinde etkileri incelenmiştir. Kadınların iş yaşamında gün geçtikçe artan popülasyonu, kendilerine ayıracakları zamanı azaltmaktadır. Bu nedenle kilo verme amaçlı kısa süreli ve etkili sonuç veren egzersiz arayışına girmektedirler. Döngüsel direnç egzersizinin fazla kilolu ve obez katılımcılarda etkisi karşılaştırıldığında her iki grupta da kilo verme açısından etkili olduğu görülmüştür.

Her iki grup kendi arasında karşılaştırıldığında 30 dakikalık dairesel döngüsel dirençli egzersizin obez grupta kilo verme açısından daha etkili olduğu saptanmıştır. Dirençli egzersizin etkileri, egzersiz yoğunluğu ile ilgili olanlar da dâhil olmak üzere çeşitli parametrelere bağlıdır. Geçmişteki araştırmalar, dirençli egzersiz programları sonrası egzersiz yoğunluğuna kıyasla kas kuvveti ve kütlesinde doz-tepki kazanımlarının olduğunu belirtmek- tedir. ${ }^{6,9,14}$ Önceki çalışmalar, düşük veya orta şiddette dirençli egzersizin yaşlı erişkinlerin sağlığı ve bağımsızlığı açısından da yararlı olduğunu göstermektedir. ${ }^{15,16,17}$ Bununla birlikte, farkl1 bir çalışma, patlayıcı direnç egzersizi ile birlikte kullanılan ağır yüklerin, yaşlı erişkinlerin kas kuvveti, güç ve dayanıklılığında iyileşme sağlamak için etkili bir yöntem olabileceğini, ancak dikkatli olunması gerektiğini bildirmektedir. ${ }^{12}$ Çalışmamızda tüm katılımcılarda döngüsel direnç egzersizi programıla birlikte anlamlı kilo kaybı saptanmıştır. Her iki grupta birden kilo kaybı görülmesine rağmen, obez grupta fazla kilolu gruba göre daha fazla bir kilo kaybı saptanmıştır. Bununla birlikte kilolu grupta kas kitlesinde artış ve vücut yăg oranındaki azalma tespit edilmiştir. $\mathrm{Bu}$ bulgular literatürdeki egzersiz etkisini destekler niteliktedir. ${ }^{18}$

Yapılan farklı çalışmalarda fiziksel aktivite düzeyinin kadınlarda daha düşük olduğu bildirilmiştir. ${ }^{19,20,21}$ Fiziksel aktivitesi düşük kadınların egzersize teşvik edilmesi obezite ve beraberinde getireceği olası sağlık problemlerinin önlenmesi açısından faydalı olacaktır. Kilo verme konusunda farklı diyet ve egzersiz türleri mevcuttur. Kullandığımız egzersiz çeşidinin kısa süreli olması ve grup halinde yapılması kadınlar için bir tercih sebebi olmaktadır. Döngüsel hidrolik egzersiz, itme ve çekme kuvvetleriyle yapılan bir antrenman çeşidi olduğu için, rehabilitasyon amaçlı, vücut yağ oranını düzenleyen, psikolojik ve sosyal açıdan da gelişimini sağlayan bir sistem olarak görülmektedir. Çalışmamızda kullanılan 30 dakika süreli aerobik destekli döngüsel direnç egzersizlerinin kilo verme konusunda etkili bir alternatif olduğunu söyleyebiliriz. Kanaley J. ve arkadaşları düzenli egzersizle birlikte vücut yă̆ oksidasyonunun artış gösterdiğini bildirmektedir. ${ }^{21}$ Bizim sonuçlarımız da literatüre paralel olarak egzersizle birlikte vücut yağ yüzdesi ve iç yağ oranının azaldığını göstermektedir. Gruplar karşılaştırıldığında obez grupta sonuçların daha etkili olduğunu gördük. $\mathrm{Bu}$ durumu obezlerde yağ oranının daha yüksek olması ile açıklayabiliriz.

Bel-kalça oranı diyabet, kardiyovasküler ve muskuloskeletal problemler gibi birçok hastalık için risk faktörüdür. ${ }^{22,23}$ Bel-kalça oranının azaltılması bu hastalıklardaki olası semptomların azalmasını sağlayacak veya hastalık oluşma riskini önleyecektir. Çalışmamızda egzersiz programımızın sonunda bel-kalça oranının da anlamlı düzeyde azaldığ kilolu grup birbirleriyle kıyaslandığında belkalça oranıyla ilgili önemli bir fark bulunamamıştır. (Kaynak)

Egzersizle birlikte kas kitlesinde kayıp oluşması istenen bir durum değildir. $\mathrm{Bu}$ durum genellikle kilo verme amaçlı spor yapanlarda beslenmelerini ciddi oranda azaltmaları veya proteinden fakir beslenmeleri sonucunda oluşur.17,24 Çalışmamızda katılımcılara özel bir diyet programı verilmemiştir. Ayrıca çalışmamızda fazla kilolu katılımcılarda kas kitlesinde artış gözlenirken obez katılımcilarda kas kitlesinde hafif azalma olduğu görülmüştür. Bu sonuçlar özellikle obez grupta kısa sürede kilo verme amaçlı ögün kesme ve azaltma, proteinden yoksun diyet yapmayla açıklanabilir. ${ }^{25,26}$

\section{Sonuç}


Zamanın değerli olduğu günümüzde 30 dakika süren aerobik egzersizle kombine döngüsel direnç egzersizleri kilo verme amaçlı kullanılabilecek kısa süreli, kontrollü etkili bir alternatiftir. Kontrollü olması, egzersiz sirasinda yaralanma riskinin az olmas1, grupla yapılması özellikle spor yapmak ve kilo vermek isteyen kadınlarda ve erişkin bireylerde daha fazla tercih sebebi olabilir. Döngüsel dirençli egzersizde maksimum verim elde etmek için kişilerin hidrolik kollara daha fazla direnç uygulamaları, maksimal kalp hızına yakın aerobik egzersizlerin yapılması ve profesyonel diyet kontörü ile daha etkili sonuçlar alınacaktır. Aerobik egzersizle kombine edilmiş döngüsel direnç egzersizleri obez ve fazla kilolu kadınlarda kilo verme ve vücut kompozisyonunu düzeltmek için etkili bir yöntemdir.

Çalışmamızda bazı limitasyonlar bulunmaktadır. Öncelikle bu çalışma kapsamında yapılan ölçümler çalışmaya kör olmayan bir araştırmacı tarafından yapılmıştır. Fakat çalışma kapsamında standart ölçüm araçlarının kullanılmasının olası ön yargıları minimalize ettiği düşünülmektedir. Bunun yanında vaka sayısının daha yüksek tutulmasının temsil edilen evreni daha fazla yansitacağ kanaatindeyiz. Ancak 12 haftalık eğitim sürecinin eksiksiz ve hatasız takibi de daha fazla katılımcı oranını zorlaştırmaktadır.

\section{Araştırmanın Etik Boyutu}

Çalışmamız için ilgili üniversitenin tıp fakültesinin Bilimsel Araştırma ve Yayı̀n Etiği Kurulu'ndan gerekli onay ve izinler alınmıştır (020-8826/2016). Çalışmamız Helsinki İlkeler Deklarasyonu'na uygun gerçekleştirilmiştir.

\section{Bilgilendirilmiş Onam}

Katılımcılara araştırma öncesinde açıklayıcı bilgilendirme yapıldıktan sonra sözlü ve yazılı onamları alınmıştır.

\section{Yazar Katkıları}

Yazarlar çalışmaya eşit düzeyde katkı sağlamışlardır.

\section{Teşekkürler}

Araştırmaya katılmayı kabul eden tüm katılımcılara teşekkür ederiz.

\section{Çıkar Çatışması Beyanı}

Yazarların herhangi bir çıkar çatışması bulunmamaktadır.

\section{Araştırma Desteği}

$\mathrm{Bu}$ çalışma sırasında, yapılan araştırma konusu ile ilgili doğrudan bağlantısı bulunan herhangi bir ticari firmadan, çalışmanın değerlendirme sürecinde, çalışma ile ilgili verilecek kararı olumsuz etkileyebilecek maddi ve/veya manevi herhangi bir destek alınmamıştır.

\section{Beyanlar}

Çalışmamız bildiri olarak 02-05 Mayıs 2018 tarihleri arasında Burdur'da düzenlenen "1st International Health Science and Life Congress”te sunulmuştur.

\section{Hakem Değerlendirmesi}

Diş bağımsız.

\section{Kaynaklar}

1. Kostrzewa-Nowak D, Nowak R, Jastrzębski Z et al. Effect of 12week-long aerobic training programme on body composition, aerobic capacity, complete blood count and blood lipid profile among young women. Biochem Med (Zagreb). 2015:103-113. doi:10.11613/bm.2015.013

2. Çetin S, Ece C, Şen M, Çetin H, Aydoğan A. The Effects of Pilates and Aerobic Exercise on Blood Pressure, Heart Rates, and Blood Serum Lipids in Sedentary Females. J Educ Train Stud. 2019;7(4):229. doi:10.11114/jets.v7i4.4077

3. Borland M, Bergfeldt L, Nordeman L et al. Exercise-based cardiac rehabilitation improves physical fitness in patients with permanent atrial fibrillation - a randomised controlled study. Transl Sports Med. 2020. doi:10.1002/tsm2.166

4. Laws A. Free fatty acids, insulin resistance and lipoprotein metabolism. Curr Opin Lipidol. 1996;7(3):172-177. doi:10.1097/00041433-199606000-00011

5. Donnelly J, Jacobsen D, Snyder Heelan K, Seip R, Smith S. The effects of 18 months of intermittent vs continuous exercise on aerobic capacity, body weight and composition, and metabolic fitness in previously sedentary, moderately obese females. Int $J$ Obes. 2000;24(5):566-572. doi:10.1038/sj.ijo.0801198

6. Takeshima N, Rogers M, Islam M, Yamauchi T, Watanabe E, Okada A. Effect of concurrent aerobic and resistance circuit exercise training on fitness in older adults. Eur J Appl Physiol. 2004;93(1-2):173-182. doi:10.1007/s00421-004-1193-3

7. Eriksson J, Tuominen J, Valle $\mathrm{T}$ et al. Aerobic Endurance Exercise or Circuit-Type Resistance Training for Individuals with Impaired Glucose Tolerance? Hormone and Metabolic Research. 1998;30(01):37-41. doi:10.1055/s-2007-978828

8. Lee S, Islam M, Rogers M, Kusunoki M, Okada A, Takeshima N. Effects of Hydraulic-Resistance Exercise on Strength and Power in Untrained Healthy Older Adults. J Strength Cond Res. 2011;25(4):1089-1097. doi:10.1519/jsc.0b013e3181c69ea1

9. Taaffe D, Duret C, Wheeler S, Marcus R. Once-Weekly Resistance Exercise Improves Muscle Strength and Neuromuscular Performance in Older Adults. J Am Geriatr Soc. 1999;47(10):1208-1214. doi:10.1111/j.15325415.1999.tb05201.x 
10. Tsai A, Wadden T. Treatment of Obesity in Primary Care Practice in the United States: A Systematic Review. J Gen Intern Med. 2009;24(9):1073-1079. doi:10.1007/s11606-009-1042-5.

11. Donnelly JE, Blair SN, Jakicic JM, Manore M, Rankin J, Smith B. Appropriate Physical Activity Intervention Strategies for Weight Loss and Prevention of Weight Regain for Adults. Medicine \& Science in Sports \& Exercise. 2009;41(2):459-471. doi:10.1249/mss.0b013e3181949333

12. Yosmaoğlu, H. B., Baltac1, G., \& Derman, O. Obez adolesanlarda vücut yağı ölçüm yöntemlerinin etkinliği. Fizyoterapi Rehabilitasyon, 2010;21(3), 125-131

13. Otman, S. A.; Köse, N. Antropometrik Ölçümler: Tedavi Hareketlerinde Temel Değerlendirme Prensipleri. Ankara,Yücel Ofset Yayınları, 2008:49-57

14. Frontera W, Meredith C, O'Reilly K, Knuttgen H, Evans W. Strength conditioning in older men: skeletal muscle hypertrophy and improved function. J Appl Physiol. 1988;64(3):1038-1044. doi:10.1152/jappl.1988.64.3.1038

15. Fiatarone M. High-intensity strength training in nonagenarians. Effects on skeletal muscle. JAMA: The Journal of the American Medical Association. 1990;263(22):3029-3034. doi:10.1001/jama.263.22.3029

16. Gibbs, James, et al. "Predictors of change in walking velocity in older adults." Journal of the American Geriatrics Society 44.2 (1996); 126-132. doi:10.1111/j.1532-5415.1996.tb02427.x

17. Henwood T, Taaffe D, Taaffe D. High-Velocity versus Conventional Resistance Training in Older Adults. Medicine \& Science in Sports \& Exercise. 2006;38(Supplement):S42. doi:10.1249/00005768-200605001-01065

18. Kalyani R, Corriere M, Ferrucci L. Age-related and diseaserelated muscle loss: the effect of diabetes, obesity, and other diseases. The Lancet Diabetes \& Endocrinology. 2014;2(10):819-829. doi:10.1016/s2213-8587(14)70034-8

19. Tunc E, İsler A. Lise ve üniversite öğrencilerinin fiziksel aktivite düzeyinin yaşa ve cinsiyete göre incelenmesi. Gazi Beden Ĕ̈itimi ve Spor Bilimleri Dergisi.2007; 12(2), 11-18

20. Aksoydan, E., \& Çakir, N. Adolesanların beslenme alışkanlıkları, fiziksel aktivite düzeyleri ve vücut kitle indekslerinin değerlendirilmesi. Gülhane Tip Dergisi,2011; 53, 264-270

21. Şanlıer, N., Konaklığlu, E., Güçer, E. Gençlerin beslenme bilgi, alışkanlık ve davranışları ile beden kütle indeksleri arasındaki ilişki. Gazi Üniversitesi Gazi Eğitim Fakültesi Dergisi, 2009;29(2).

22. Kanaley J, Cryer P, Jensen M. Fatty acid kinetic responses to exercise. Effects of obesity, body fat distribution, and energyrestricted diet. Journal of Clinical Investigation. 1993;92(1):255261. doi:10.1172/jci116559

23. Vazquez G, Duval S, Jacobs D, Silventoinen K. Comparison of Body Mass Index, Waist Circumference, and Waist/Hip Ratio in Predicting Incident Diabetes: A Meta-Analysis. Epidemiol Rev. 2007;29(1):115-128. doi:10.1093/epirev/mxm008

24. Welborn T, Dhaliwal S, Bennett S. Waist-hip ratio is the dominant risk factor predicting cardiovascular death in Australia. Medical Journal of Australia. 2003;179(11):580-585. doi:10.5694/j.1326-5377.2003.tb05704.x

25. Stenholm S, Harris T, Rantanen T, Visser M, Kritchevsky S, Ferrucci L. Sarcopenic obesity: definition, cause and consequences. Curr Opin Clin Nutr Metab Care. 2008;11(6):693-700. doi:10.1097/mco.0b013e328312c37d

26. Frimel T, Sinacore D, Villareal D. Exercise Attenuates the Weight-Loss-Induced Reduction in Muscle Mass in Frail Obese Older Adults. Medicine \& Science in Sports \& Exercise. 2008;40(7):1213-1219. doi:10.1249/mss.0b013e31816a85ce 